\title{
Health-seeking in Tuberculosis: A Frustrating Undertaking in Rural Nepal
}

\author{
Ulla-Britt Engelbrektsson $^{1}$ and Madhusudan Subedi ${ }^{2}$ \\ 1. University of Gothenburg, Gothenburg, Sweden \\ 2. Central Department of Sociology, Tribhuvan University, Kathmandu, Nepal
}

\begin{abstract}
In focus are delays in health seeking in connection with tuberculosis in rural Nepal. A longitudinal in-depth field study made it possible to research individual actions and processes in relation to those of relevant others. Moreover, the approach facilitated the tracing of clustering of cases over time and patterns of health-seeking processes within these. The overall picture is one of long delays. The reasons for the lengthy delays were not inactivity from the patient side but rather the opposite: a frantic search for help during which they were led astray more often than helped!
\end{abstract}

Key words: Tuberculosis, Nepal, health-seeking processes, delays.

\section{Introduction}

In Nepal, approximately 40,000 annually develop active tuberculosis (TB) and 5,000-7,000 die from the disease $^{1}$. In this presentation the focus is on the health-seeking processes. The field data originate from in-depth social anthropological research in 2005, 2012, and 2014 in a rural community in western Nepal ${ }^{2}$.

Bio-medically TB is an infectious disease caused by Mycobacterium tuberculosis. The disease usually affects the lungs (pulmonary TB) but can also occur in other parts of the body (extra-pulmonary TB). Approximately half of those who develop the disease are potentially infectious. Those are patients with sputum-smear positive pulmonary TB. Infection is air-born. The main symptoms of pulmonary TB are: cough for two weeks or more; low-grade fever; blood stained sputum; chest pain. The signs of extra-pulmonary TB (EP TB) depend on the organ involved. Signs and symptoms common to both types are: loss of appetite; loss of weight; weakness of body.

In 1995, in the fight against TB, Nepal aligned itself with the WHO's global policy prescription of Directly

Corresponding author: Ulla-Britt Engelbrektsson, research field: social anthropology.
Observed Treatment, Short-course (DOTS). The National Tuberculosis Programme (NTP) has since made exemplary progress with anti-TB services widely available through the general health services but also through NTP partner organisations. For some years, however, the prevalence and the mortality rates have not decreased at the speed hoped for. Presently, active drug-sensitive TB is treated with a standard six-month course of four anti-microbial drugs.

There are several studies of various aspects of TB in Nepal, health seeking processes included ${ }^{3}$. With few exceptions the latter are quantitative in nature with data mainly drawn from one-time interviews in DOTS treatment centres. In contrast, the data of the present study originate from a repeated in-depth community study in which individual actions are researched in relation to those of relevant others. Moreover, prolonged stays in the field ensured well grounded information on the role of home remedies and traditional healers. And, the longitudinal approach facilitated the tracing of clustering of cases over time and patterns of health-seeking processes within these.

The fieldwork was carried out in Kanlagaun, a large-sized community/village in the Surkhet district, south-east of the regional headquarters (the town of 
Birendranagar) ${ }^{4}$. Administratively the village is part of the Ghockchock Village Development Committee (VDC). To reach Birendranagar with its wide range of medical services, such as the District Hospital (later transformed into the Mid-Western Regional Hospital), takes 3-4 h on foot or one hour by vehicle.

\section{The Research: Theory and Methodology}

After the Second World War, the World Health Organization was established and large-scale plans for an international combat against suffering and disease by the spread of biomedical services were launched. When international public health workers started to realise that indigenous peoples did not necessarily perceive the benefits of scientific medicine, many jumped to the conclusion that it was because of cultural and social barriers rooted in the traditions of the target group members. Soon, however, it became apparent that at least as many of the early resistances encountered were as rooted in the medical profession and in health bureaucracies as in the target peoples. Meanwhile, the notion of 'rational man' purposefully avoiding variance with established cultural rules/cognitive maps was being questioned by anthropologists, a main argument being that humans are not likely to intellectualise their behaviour in the sense of making everything consistent. Moreover, humans tend to embrace multiple ideas, values, and goals with some drawn upon in one set of circumstances but not necessarily so in another. The utilisation by one and the same person of differing medical systems for one and the same occurrence of ill-health was and is a case in point. In Nepal, bio-medicine is a late-comer. The present major medical systems are Ayurveda, Shamanism, and Biomedicine, each representing specific ideas of causation and treatment options.

Healthcare seeking is influenced by a number of factors. Researchers commonly distinguish between factors ascribed to the patients versus those of the health system. In this study the health system factors are identified in accordance with the health care system sectors outlined by A. Kleinman [1]. He suggests that in most complex societies, the health care system (the social construction for the care of the sick) can analytically be divided into three, partly overlapping, sectors-'the popular', 'the professional', and 'the folk'. The sector which Kleinman calls 'the popular' is the lay local sphere comprising individuals, family and friends. The sector called 'the professional' comprises the organised, legally sanctioned, healing professions (paramedics included). Meanwhile, 'the folk sector', is characterised by the non-bureaucratic specialist. In this sector, certain individuals specialise in forms of healing which are either sacred or secular, or a mixture of the two.

In Kanlagaun and its immediate surroundings there were formal interviews with patients and with one household member and one next-door neighbour of each patient formally interviewed ${ }^{5}$. In addition, there were observations and formal and informal talks with local health workers, key informants, and other community members. Thus, there were multiple sources of information and verifications.

The field research in 2005 as well as in 2012 amounted to a month and an half and in 2014 to one month, with visits in between ${ }^{6}$. At each occasion, in preparation for the field work, TB registers and treatment cards for the last 7 years in likely treatment places were scrutinised for possible patients from Kanlagaun. In 2005, close to 30 patients were thus identified. However, some of them had moved out of the village and others were abroad. In the end, 18 patients within the village and its immediate vicinity were enrolled. In 2012, the households of the patients from the 2005 study were revisited and 11 patients from the intervening 7 years were identified, contacted, and interviewed. Later, in 2014, the patients interviewed in 2012 were followed up and another 9 cases were included. The overall male/female ratio was $2: 1$.

\subsection{The Community}

Kanlagaun stretches south-west to north-east over a 
valley, a hill side, and a hill top. To walk across takes fifteen minutes but from bottom to top close to one hour. There are three distinct hamlets along the path which runs from the bottom to the top. The first known settlers were 50-60 Magar families from a village further east who arrived in the upper part in $1870^{7}$. Below was a forest which served as grazing grounds for the cattle of nearby villages, rich in sweet potatoes (which ensured the settlers' survival) but also in malaria mosquitoes. Later a cholera epidemic swept the area and many died in Kanlagaun and in neighbouring villages (freeing the forest). The Kanlagaun survivors concluded that the goddess they had brought with them, Sulte Devi, was not strong enough to protect them in the new place and it was decided to also pay tribute to the ancient area goddess, Khara Devi.

Over the years, there was a gradual clearing of the land below the settlement and parallel to that a step-by-step move down the hillside and a speedier one after the lower parts were sprayed with pesticides. Concurrently, some families (mostly of a non-Magar background) moved in and others moved out of the village (mainly to the Tarai in the south).

\section{The First Study, 2005}

At the time of the first stay, the village population was nearly 2,000 with Magars in a clear lead. Most Magar houses were half-way up the village territory. Above were mainly Dalit houses and below chiefly Brahmin houses (late arrivals) but also a cluster of Dalit households. In 2005, the forest was all but gone. The residents were farmers with a few animals for work, food, and manure, but there were also ex-army pensioners. Moreover, several households had a member working abroad, mostly in India but "when lucky" in Malaysia or Dubai. The overall picture was a mixture of those who had enough and those who did not. The Dalit households were the poorest. Religiously, most were Hindus or Buddhists or a mixture of the two and of late there was a growing number of Christians. The communal spirit was reported to be exceptionally good with donations gathered whenever a household was in serious trouble. About TB, the general opinion was that it was rare in the past but presently increasing. However, whereas previously people died from TB, this was no longer the case.

There were about a dozen practising dhami (divination, mantras, low key exorcism) but no jhankri (advanced exorcism). 'The uneducated ones' when sick, it was said, went to the dhami/jhankri whereas the more knowledgeable ones went to the Health Post or a hospital.

Only a few months prior to the first field work, the Sub-Health Post in the VDC centre, 15-20 min from the lowest part of Kanlagaun, had become a Sub-DOTS centre. Before that the TB treatments were either from the DOTS centre of the District Hospital or the INF TB Hospital, both in Birendranagar, or from a Health Post on a hill top in an adjacent $\mathrm{VDC}^{8}$. There was no private pharmacy in the immediate area but several in the regional headquarters, and so were a few nursing homes.

Of the 18 patients in focus in 2005, two-thirds were Magars. The youngest was 13 years at registration and the oldest 70 years, with a mean age of 39 years. Thirteen were diagnosed as pulmonary sputum-smear positive (potentially infectious) and the rest as EP cases. Seven were on treatment whereas 11 had completed their treatments.

\footnotetext{
${ }^{1}$ The National Tuberculosis Centre's web site, October 2015.

${ }^{2}$ Approvals of the research were granted by the Nepal Health Research Council. The field work was made possible by grants from the Swedish Research Council and the University of Gothenburg, Sweden.

${ }^{3}$ Of special interest for this study are the reports by Ten Asbroek et al. from 2008, Basnet et al. from 2009, Bhatt et al. from 2010, and Kumar from 2013.

${ }^{4}$ To protect the anonymity of persons and institutions, the names of the village and the VDC have been altered.

${ }^{5}$ After informed consent.

${ }^{6}$ Most field data was assembled by Mr, Tek Bahadur Saru, an INF health-worker of long standing (TB, Leprosy and Community-Based Rehabilitation).

7 The Magars constitute Nepal's largest 'ethnic group'. In the 2011 Population Census they numbered 1.9 million.

${ }^{8}$ The International Nepal Fellowship (INF) has supported TB work in Nepal since 1953.
} 
The shortest (0.5 month) and the longest patient reported delays (1.5 years) were within one and the same family, together with one of the in-between ones (5 months). The first registered of the three, a middle-aged man, was the one with the shortest delay. He was diagnosed 15 months prior to the interview, a sputum-smear positive case. He suggested that it had all been very straightforward. Suddenly there had been blood in his mouth and after that a fever. Since the fever persisted he had made his way to the nearest Health Post. They took 'cough tests' (sputum-smears) and had it sent to the District Hospital and a week later he was told to start his TB treatment. He said that the diagnosis was not a complete surprise as he had heard about TB over the radio. Eight months later he was registered as 'cured'. Half a year after his cure, his eldest daughter-in-law was registered as an EP abdominal TB case. Her route to diagnosis and treatment was far from straight. Her health-seeking story was extreme compared to most others but less so to those diagnosed as EP TB cases. She consulted three dhami (one after another), had three check-ups at the hill top Health Post, two visits to a government hospital in a nearby district, and three to various pharmacies in Birendranagar before she in one of the nursing homes, after numerous tests, was told that the TB disease had been found in her stomach. At the time of the interviews, her youngest brother-in-law, 18 years of age, was also on TB treatment. He was diagnosed three months after his sister-in-law. In his case, as mentioned, there were five months between the alleged initial symptom and the start of treatment. His health-seeking process started at the nursing home where his sister-in-law's TB had been diagnosed. The treatment recommended for him, however, did not change his condition. The next step was the hill top Health Post where he had sputum-smears taken but without a forthcoming diagnosis. After that there was a visit to the District Hospital where he was told that it was typhoid. Finally, his father brought him back to the nursing home and after yet some tests he was diagnosed as EP TB, pleural effusion. In 2012, we learnt that he was well and had joined the Nepali Army. His father was also doing well and so was his sister-in-law.

The person with the second shortest delay, one month, said that the comparatively short time between initial symptoms and the diagnosis was because his elder son had recently had TB, so he suspected his own illness to be the same. "The family", he said, "brought me straight to the 'TB hospital' (INF, Birendranagar)”. During the interview he made a point of there not having been any dhami/jhankri work. We thought it meant that he had not consulted a dhami/jhankri. Later, however, we learnt that he was a dhami himself and had been so for a long time. In 2012 he was in good health, working his fields as well as functioning as a dhami.

Another interviewee who stressed that there had been neither dhami/jhankri work nor any jadibuti (herbal concoctions) was a British army pensioner. He had the third shortest delay, two months. He said that he had gained some knowledge of TB from the Army and "I told my family to bring me straight to the TB Hospital, and so they did”. In 2012, his family reported that he had been cured from TB but had later developed asthma and from this he had died.

The reported delay of another elderly patient was 13 months. After a month of ill-health he consulted a dhami. Over time, a goat and several chickens were sacrificed. The next step was a visit to a nursing home in Birendranagar where he had an X-ray and other tests. A week later, there was another X-ray and he was told that additional medicines were needed, injections included, but there was no improvement. "At this stage", he said, "I thought I will surely die". Two months later he suddenly had a high fever and family members brought him to a private Medical College down on the Tarai where he was diagnosed as a sputum-smear positive case. He had his TB medicines from the hill top Health Post. "Every Monday”, he said, "I sent my son or my daughter-in-law for the medicines". He died within a year and an half. His wife 
said that he never got well from his TB and that TB was the cause of his death.

From the remaining Magar cases a few sundries:

The neighbour of one said that he had noticed that when "the sick person has TB of the lungs it is usually quickly found but TB disease in other parts of the body is difficult to know".

The youngest patient in the cohort, 13 years of age at the time of diagnosis, had a three-month delay. She told that long ago her paternal grandmother had been treated for TB, but had died while on treatment. In her own case, various home treatments were tried before her parents brought her to a pharmacy in Birendranagar where they were told that it was pneumonia. Still later, her parents brought her to the INF 'TB Hospital' and there her TB was diagnosed.

A Magar man, one of the teachers in the village, 35 years of age, had a three months delay. He went to the Sub-Health Post at an early stage and they gave him medicines for fever. As the symptoms persisted, he decided to fight what he thought might possibly be a strong cold with a 'hot diet' (intrinsic quality): honey and chicken soup. Later he tried jadibuti, some he ate and some he applied on his body but with no lasting effects. In the end, he was diagnosed at the INF 'TB Hospital'. He had suspected TB, he said, because of the symptoms, even so "it was bad news as TB is a big disease and I was discouraged".

Two months prior to the teacher, a 26 years old Magar woman, was registered for TB treatment. She had a swelling on her neck. When it increased there was fever and pain, and when it decreased no fever and no pain. In the house there were some medicines for fever and she took these but there was not improvement. Her husband brought her to the Sub-Health Post where she got medicines for fever but was also told to go to the District Hospital for a check-up. After yet some time, her husband brought her to Birendranagar but not to the District Hospital but to one of the nursing homes where they eventually diagnosed her condition as gland TB.
One of the Magar men, 35 years of age, on treatment at the time of the interviews, had a delay of nine months. The diagnosis, he said, was a complete surprise and he was sad that the disease which was not in his family, "had come to attack him". The neighbour suggested that the reason for his condition was too much drinking, smoking, and staying up late at night. His health-seeking process had started at the District Hospital. Then, his parents enrolled a local dhami. After that he consulted a jhankri, and then a dhami from another village. In between, there was a visit to a pharmacy in Birendranagar. Meanwhile, he got steadily worse. A cousin of his from outside the village came for a visit and speedily arranged for him to be brought to one of the nursing homes in Birendranagar, where he was diagnosed as a TB case. After 'cure' he went to India to work in order to pay the debts which had mounted while he was sick. In 2012, his younger brother reported that seven months later he was back, seriously sick and was diagnosed as 'a relapse case'. Two months into the re-treatment there was jaundice and, according to the brother, he died because of the jaundice.

In 2012, we learnt that another of the Magar patients of the 2005 interview cohort, a man in his mid-thirties, had also died, but according to his brother not because of TB but because of AIDS. Three months after the start of symptoms he had been diagnosed as EP skin TB. By then he had painful and burning pimples from his neck to the waist. He had had several visits to a dhami and tried a number of herbal concoctions. His elder brother brought him to a pharmacy in Birendranagar where he was given ointment and tablets, but again without the desired result. Finally, his TB was diagnosed in one of the nursing homes. In 2005, his wife said that her husband's health was improving but she herself had severe stomach pain, did not feel like eating, and had suddenly lost a lot of weight. In connection with this she had been to the District Hospital and been advised to return a few days later for test results, 'cough tests' included. Her sputum-smear 
tests turned out to be positive. In 2012, we learnt that her husband had died shortly after the completion of his TB treatment, according to his brother, as mentioned, because of AIDS. Moreover, not long after him, his wife had also passed away because of AIDS or perhaps $\mathrm{TB}$, we were told.

Clearly evident in the data is the clustering of TB among the Magars interviewed, a circumstance likely connected with dense socialising in smaller segments. A similar situation was found within a Dalit ward, 'the Tailor ward', situated below the main Magar hamlet. The houses in this ward were and are very close to each other. Most residents were of the tailor caste, yet in 2005 only two of the twenty households had their main income from tailoring. There were four patients from this ward within the 2005 interview cohort.

The first diagnosed was a young man, one of the few who did work as a tailor. At the time of the TB diagnosis he was completely bedridden. Before that he had been to a local dhami, to a private pharmacy where he was told that it was typhoid, and to the District Hospital where he was told it was malaria. In the end he was brought back to the District Hospital and from there he was referred to the INF 'TB Hospital' where he was diagnosed as a sputum-smear positive case. His father, he told, had had TB 26 years earlier. In 2012, he was not back to full strength, tired easily, and was not able to work a full day.

The next was a 70-year-old man. Ten years earlier his wife had been started on anti-TB treatment. She, however, died early in the treatment. He himself was sick for four months before diagnosed at the INF 'TB hospital'. Before that, he had been to the Sub-Health Post but had been wrongly diagnosed. "No dhami/jhankri and no jadibuti”, he said.

Half a year after the old man's completion of treatment, his eldest daughter-in-law was diagnosed with EP gland TB. At the time of the interview she was two months into the treatment. Her signs and symptoms were quite different from that of her father-in-law's yet at the start of her symptoms he was the one who advised her to speedily go for a medical check-up. However, before doing so she had several sessions with a dhami. She then went to the Sub-Health Post, then to two different pharmacies in the district headquarters, then to a Health Post in another VDC, and then to yet another pharmacy. Only after all these help-seeking efforts did she end up at the District Hospital and was diagnosed as gland TB. In 2012 we learnt that her father-in-law had died two years after 'cure' but not because of TB but of a stroke. In 2012, on and off the daughter-in-law had swellings in her neck and there was pain. We strongly advised her to return to the hospital for a re-examination.

Before the daughter-in-law, a friend and next-door neighbour of the old man had fallen sick with roughly the same signs as those of the old man. Yet, it took seven months before he was properly diagnosed. Before that he had been to several pharmacies, had tried jadibuti, had consulted a dhami and visited a Health Post in a neighbouring district. Finally, when there was blood in his cough, 'the old man', advised him to go to the District Hospital for "a cough test" and so he did and was found to be highly sputum-smear positive. His wife, as well as a neighbour, said it was good that the disease had been found at such an early stage. They obviously counted his disease from the time of the blood in the cough and not from the start of the persistent coughing and other signs. In 2012, he testified to no more trouble because of TB but there were spells of dizziness and for this he was in consultations with a dhami and with a jhankri and had home-made jadibuti on the side.

Another patient in 'a low-caste' position, a female, was from the hamlet on top of the hill. She was 35 years of age at the time of the interview. In her case, as in the case reported on immediately above, the delay between the first acknowledged signs and the start of TB treatment was seven months. In between she had visited a government Health Post and a pharmacy in the district headquarters. Her TB was finally diagnosed at the INF 'TB Hospital'. In 2012, she said that she had no 
further TB problems but there were breathing difficulties, heart palpitations, and stomach pain. For these troubles she was treated by a dhami.

The only high-caste patient in the interview cohort, a Chetri man, 50 years of age, started off by telling us that he had neither turned to a dhami nor to a jhankri because he did not believe in them. Further into the interview, however, we learnt that when he had returned sick from India his parents had arranged for an elaborate three-day jhankri session. Shortly afterwards, a private physician diagnosed malaria, a disease which he and his parents were told was caused by 'minute malaria animals'. Having started the medication he was happy to notice that they exited with his stool. Four months later, he was carried into the INF 'TB Hospital' in a critical condition. In 2012 we learnt that he was doing well.

\subsection{Comments}

Except for the two extremes the mean reported delay was 5.1 months. This, however, was from a patient perspective. Commonly, others would learn of signs and symptoms only as these became undeniable and thus, from non-family members' positions, often a short delay. Whereas in reality, from a medical and epidemiological point of view, a dangerously long hold-up, resulting in those affected being in a disease-advanced state at the start of anti-TB treatment, some not even making it, and in the case of potentially infectious TB, a broad window for disease transmissions. Moreover, 'actual hold-ups' are likely to have been longer with early signs/symptoms missed or not recalled. The reasons for the lengthy delays, as evident in the text, were not inactivity from the patient side but rather the opposite: a frantic search and shopping around for help during which they were led astray more often than helped!

Spontaneously, home remedies were rarely mentioned. Yet, they were not absent but rather taken for granted, the health-seeking within 'the popular sector' that is. In former days illnesses were categorised as 'hot' or 'cold' and so were food items (intrinsic qualities) and there would be attempts to balance a 'hot condition' with 'cold food' and vice versa (Ayurvedic principles). In 2005, such ideas were still around but not habitually adhered to. In connection with unrelenting illnesses, however, they often were, at least to some degree. Thus, in connection with a persistent fever like in TB ('a hot condition') there would be yellow lentils ('cold') rather than red ones ('hot'), and so on. Jadibuti, herbal concoctions (Ayurvedic inspired) were commonly put to use, but again spontaneously rarely mentioned. Roots, grass, leaves, and pieces of bark were gathered, prepared, consumed or applied. There was no formally trained Ayurvedic specialist in the village and its immediate surroundings but there were some with more knowledge of herbal regimes than others and such a person might be consulted when household concoctions did not do the trick.

There were two main routes of help-seeking outside the home: 'the old/traditional one', in Kleinman's terminology within 'the folk sector' and 'the new/modern one', the one within 'the professional sector'.

The two local goddesses were mainly approached/appeased for the general well-being of the community rather than for individual cases of ill-health. Approximately half the patients reported that they had had sessions with traditional healers, mostly a dhami/jhankri. The real proportion is likely to have been higher as the villagers were well aware that in 'modern Nepal', traditional healing methods are disapproved of. The traditional healers were approached for various problems not only for human illnesses. They were close by, familiar, easily available, and an initial consultation likely to be free. For the TB patients, the consultations with dhami/jhankri were a delaying factor and, in the long run, often a costly affair. No one suggested that the sessions had had a lasting positive influence upon their condition. And, no one reported that the healer/s had advised them to seek 
biomedical help. The average delay, of those who reported that they had been to traditional healers was double that of the others.

But, there were also delays caused by faulty diagnoses and treatments by biomedical health care professionals, public as well as private. Those delays were not as long as the 'traditional healer delays' but even so, too long. At the same time, many of those encountered within the professional biomedical sector were not doctors but paramedics or unqualified health workers. Of the patients interviewed in 2005, more than two thirds were wrongly diagnosed/medically treated at their first visit to a biomedical establishment!

The number of visits to pharmacies was staggering. In 2005, those frequented were all in the district headquarters. The consultations were free of charge but getting there and back was costly and so were the many medicines recommended. Moreover, remedies were suggested per symptom rather than holistically. Only in the nursing homes were physical examinations carried out, sometimes efficiently, sometimes not. In the nursing homes, a great number of tests were carried out and the bills mounted. Thus, often they were not the first choice within the private sector.

The District Hospital was also in the district headquarters and an examination there plus the recommended treatment were likely to be less expensive. Yet, the Kanlagaun villagers, like many others, initially aimed for the private sector. A major reason was expectations of superior services: to be addressed in a nicer way, immediately seen to, good medicines, and so on. The 'INF Hospital', also in the district headquarters, was a TB hospital only and thus not a place for general consultations. However, unlike most of the other healthcare facilities consulted, it was a place where a TB diagnosis was not likely to be missed.

Eventually, 8 of the 18 patients interviewed were diagnosed as TB cases through the INF 'TB Hospital', 6 through a private nursing home, 3 through the government health services and 1 from Kohalpur
Medical College (private teaching hospital outside the district).

With each failed treatment there were dashed hopes along with increasing physical suffering and mounting expenditures. Thus, even when known as 'a big disease' and a somewhat shameful disease, the TB diagnosis tended to be a relief, particularly as it was known that the government provided TB medicines free of charge. The latter meant effective treatment and healing and most of them did recover, some, however, not as fully as wished for. Moreover, as mentioned, there were two deaths within the cohort ascribed to TB. In both cases, according to their families, not because the medicines did not work but because the person was diagnosed too late!

\section{The Second Study, 2012 and 2014}

The village of Kanlagaun seemed more affluent in 2012 than in 2005. Households with an income from abroad, beyond India in particular, had upgraded their living standards. The mobile phone era was evident by people walking around with phones in their hands but also by a high telephone tower in the lower part of the village, the Brahmin part. Men could be seen ploughing with a train of oxen while concurrently conversing over their mobiles. The old and the new were also evident in that, roughly parallel in time to the erection of the telephone mast, a new temple had been built for Khara Devi, the ancient area goddess. In the new temple homage was also paid to Sulte Devi. The temple situated on a hill reached a little further up into the sky than the telephone tower.

In 2012, it was said there were "one hundred dhami/jhankri" in the VDC; plenty of them, perhaps even too many! Earlier, we were told, everyone consulted the dhami but nowadays in the case of ' $\mathrm{a}$ normal disease' the first choice was likely to be the Health Post with the traditional healer as a second or a third choice. Moreover, if a person reported blood in the sputum or cough, the dhami was likely to suggest that he/she should go for a medical check-up. The latter 
because the District Health Office had given them three days of health teaching, basic TB training included.

For most Kanlagaun villagers the nearest government health care service was the Sub-Health Post in the VDC centre. The villagers said it functioned well for minor troubles but in more serious cases help was sought further away. Immediately opposite the Sub-Health Post a private pharmacy had opened. The owner was a local man, medically trained within the Maoist fold during the insurgency (which was held against him and his business by some). Contrary to the Sub-Health Post its services were available $24 \mathrm{~h}$ a day. Meanwhile in Birendranagar, there had been a steady increase of pharmacies and nursing homes. The INF 'TB Hospital', however, had closed (late 2005).

In late 2012, only two Kanlagaun TB patients had their anti-TB medicines from the hill top Health Post of the adjacent VDC, both from the upper part of the village, whereas the rest had theirs from the VDC's Sub-Health Post, recently upgraded to 'Health Post'. The Health Post in-charge (rarely present) was from the outside but other staff were locals. They suggested an increase in TB. The reason supposedly being more alcohol which in turn was linked to more money being around. The idea of an increase in TB cases was also voiced by others. The TB registers, however, did not back it up. According to the official registers, the number of new cases in the VDC oscillated between 15 to 20 per year and had done so for the last 6 years. Some cases, however, might not have been entered into the registers.

In 2013, the VDC Health Post became a DOTS centre in its own right. However, without any greater change from before; TB medicines were distributed but not much more than that. Contact examinations were not on the agenda and there were no follow-ups after treatment. There was missing information on most treatment cards.

In 2012, as in 2005, TB registers and treatment cards for the last 7 years, (2005-2012), in likely treatment places, were scrutinised. Eleven Kanlagaun patients were identified and interviewed and so were a household member and a next-door neighbour of theirs. Also, as previously, there were informal talks and interviews with local health staff and various community members. The youngest in the patient interview cohort was 25 years of age and the oldest 67 . Seven were diagnosed as pulmonary sputum-smear positive, 2 as pulmonary sputum-smear negative, and 2 as EP cases.

In 2014, we decided to revisit those interviewed in 2012 and to increase the number of patients in the study. Thus, another 9 households with a TB patient from within the last 7 years were included. Most of those were approached because we knew that in one way or another they were associated with patients interviewed either in 2005 or in 2012. The combined 2012 and 2014 study cohort thus encompassed 20 patients of which 12 were males. The mean age was 39 years. Fourteen of the 20 were of Magar origin.

Contrary to our expectations, the reported delays were not shorter than those of 2005 and that in spite of almost all of the 2012 and 2014 patients interviewed having or having had a recognised TB patient close by and in spite of most new cases being pulmonary ones (mostly quite easy to diagnose).

In the 2005 study half of the patients reported that a family/household member had or had had TB. The proportion was roughly the same among those interviewed in 2012. However, more next-door neighbours were involved, and thus the TB clusters were larger.

\subsection{One Cluster}

The first patient interviewed in 2012 was a young Magar male. He was first cousin to the man interviewed in 2005 who reportedly had died of AIDS half a year after the completion of his treatment for EP skin TB. The man of 2012 was diagnosed three years after the death of his cousin. Shortly before him, his own father had been started on TB treatment. And, one and an half years later, their next-door neighbour, a 
close friend of his father, 50 years of age, was registered as a TB case. Another six months down the line, so was a 29-years-old female neighbour of theirs and eleven months further on a male neighbour, 27 years old. The wife of the latter had been on TB treatment two years earlier and prior to both so had his father. Within this cluster, there were two other patients of the 2005 cohort. One was the school teacher. The other was the Chetri patient who having started anti-malaria treatment was happy to discover that 'the minute malaria animals' exited his body with his stool. Six years later, his closest neighbour, a man 50 years of age, was diagnosed as a TB case.

The father of the first patient interviewed in 2012 said that his delay was "only a few weeks, possibly one month". However, it might have been longer as he had first tried various home treatments, had been misdiagnosed at the Regional Hospital, and only after that was his sputum-smear positive TB diagnosed in one of the nursing homes in Birendranagar. His son, the first patient interviewed in 2012, had experienced that something was amiss because of "uneasiness in my scrotum, pain and swelling". In no way did he connect his ailments with his father's condition or with TB. He did not attempt home remedies or traditional healing but approached a pharmacy in Birendranagar and after that one of the nursing homes where he initially was treated for a hernia but later told that it was likely to be TB. His reported delay was four times that of his father. Their next-door neighbour, the close friend of his father, was diagnosed a year and a half later. He had a delay of 12 months during which he just about tried it all; home remedies, several consultations with dhami/jhankri, a couple of visits to the VDC Sub-health Post, and one to the Regional Hospital, before he was brought to a private clinic down on the Tarai where he learnt that he had TB of the spine.

The 29-year-old female diagnosed six months later, had the typical signs of pulmonary TB. Her first health-seeking effort outside the home was a visit to the VDC Sub-Health Post where she got medicines for cough and fever. After that, she visited a pharmacy in Birendranagar. And, only after that did she turn to the Regional Hospital where her TB was diagnosed, reportedly five months after initial symptoms. She said that the diagnosis was completely unexpected and she was shocked, wondering where on earth she had picked it up.

The next person diagnosed with $\mathrm{TB}$ within the cluster was the one whose wife had had TB two years prior to him. Her clinic treatment card was not found. She had a reported delay of nine months. Part of the reason for the long delay was that her husband was away in India at the time, the children were small, and she had difficulties leaving the house. She visited the pharmacy in the VDC headquarters and a local dhami until someone suggested that she should try the Christian church (to be prayed for) and so she did. She did not get well but joined the church. A month later her father and maternal grandfather brought her to the Regional Hospital where her TB was diagnosed. Contrary to her case, her husband's delay was short, reportedly one month only. He was living in Birendranagar at the time, working as a welder. His wife, he said, pushed for early treatment. Thus, shortly after the first symptoms he approached a pharmacy. They gave him typhoid medicines. As he did not improve he turned to the Regional Hospital where they checked his blood and X-rayed his lungs but no sputum tests. Even so, he was registered as a pulmonary sputum-smear positive case. In 2014, his father willingly shared his ideas and thoughts about the TB of his son and his daughter-in-law but only in passing did he mention that he himself had been treated for TB prior to them.

The next door neighbour of the Chetri patient interviewed in 2005 was a Brahmin. He reported a delay of 12 months. His wife, he said, requested him to seek treatment at an early stage but they were low on money. Thus, only after some months did he approach a pharmacy in Birendranagar and only after yet more months another one. As he was getting worse, his 
neighbour, the Chetri, suggested that it might be TB and advised him to turn to the Regional Hospital. Eventually he did and learnt that so it was. He said he was happy with the diagnosis because they were out of money and TB treatment was free of cost and he had good faith in the TB medicines. In his case, however, the treatment was prolonged as there was no sputum conversion after the initial two months.

\subsection{Another Cluster}

Among the patients interviewed in 2012 was a 60-year-old Magar woman. She was part of another cluster, one primarily connected with the upper part of the village. Her brother had TB before her and was among those interviewed in 2005 (the British army pensioner) and so was a Dalit female neighbour of hers. In 2012, we learnt that five years later the female neighbour's brother-in-law had developed TB. He was treated not once but twice as he had a relapse. His relapse was registered a year and an half before the TB diagnosis of the 60-year-old Magar woman. Three months after her, a middle-aged male relative of theirs in the immediate neighbourhood was also found to have contracted TB. And, 16 months later so was a daughter of the 60-year-old Magar woman. The daughter, 38 years of age, was on treatment during the interviews in 2012. In 2005, another patient from the upper part of the village had also been interviewed. He was the man whose son and daughter-in-law used to pick up his medicines from the hill top Health Post. He, as reported, died shortly after having completed his treatment. Two and an half years later, his son was registered as a TB patient and a year further on, so was his daughter-in-law. We interviewed her in 2014. Her father-in-law, had been a close friend of the British army pensioner.

The 60-year-old Magar woman, the sister of the British army pensioner interviewed in 2005, had a reported delay of eight months. She had the typical signs of pulmonary TB but also problems with her stomach. Her husband was a dhami and he did his best to cure her with the very kind of treatments disapproved of by her brother (the British army pensioner). The next step was a visit to the Sub-Health Post where they were advised to go to the Regional Hospital. They, however, were low on money and only some months later did they have enough. By then, her weight was $28 \mathrm{~kg}$. She ended up with prolonged anti-TB treatment as there was no sputum conversion after the initial two months and because of a pause in the treatment due to jaundice. In 2012, she was not convinced that she was completely cured as she still had trouble with her stomach and there was some jaundice.

The middle-aged relative and next-door neighbour of the 60-year-old Magar woman, was diagnosed three months after her; a pulmonary sputum-smear negative case. His reported delay was three months. His first port of call was a pharmacy in Birendranagar. The next was the Regional Hospital where he was examined first by one and then by another doctor and eventually diagnosed as a TB case. He reported that the TB diagnosis had not been a complete surprise as there had been several neighbours with TB.

The reported delay of the married daughter of the 60-year-old Magar woman was three years. She was diagnosed as a sputum-smear positive case, just like her maternal uncle and her mother before her. And, like her mother, she had prolonged treatment because a lack of sputum-smear conversion after two months. To the question of why such a long delay she said that she had not been equally sick the whole time and when worse than at other times she thought it was because a weak constitution, having a cold, and not eating well. Approximately once a month there had been blood in her mouth but she had not known or understood why. She had been shy about the whole thing. When her condition became acute her husband was in India. Her daughter together with a relative carried her to Birendranagar but not to the Regional Hospital, where her mother and her maternal uncle had been diagnosed, but to one of the nursing homes. The neighbours said 
that the long delay was because a lack of money. She expressed that her TB probably was a transfer from her mother. The reported initial signs and symptoms of hers, however, were well ahead of those of her mother.

The man who together with his wife had picked up his father's TB medicines from the hill top Health Post was abroad at the time of the interviews. Thus, we did not meet him but we did meet his wife. She was registered as an EP, pleural effusion case. Her reported delay was one month only. Unlike in the case of her father-in-law, there were no visits to the dhami. She told that her husband, himself TB diagnosed a year earlier, straight away brought her to a nursing home in Birendranagar and there they learnt that it was TB. Because of what had happened to her father-in-law the diagnosis made her afraid, she said, but she also knew of others who had recovered well, her husband included, so "I was not without a hope". She knew about germs and thought her TB was a transfer from her father-in-law and from her husband. At the end of the household member interview, the mother-in-law unexpectedly told us that several years earlier, she herself had been seriously ill and there had been blood from her mouth. Her husband had brought her to the District Hospital where they had checked her sputum but nothing more had come out of it, and presently, that is in 2014, she was doing well and so was her son in Dubai. The daughter-in-law, she added, was also doing well.

\subsection{More Clusters}

The other TB clusters were not as sizeable as the two mentioned above but similar in composition and construction; TB in various forms within families, between members of related families, and among next-door neighbours. And, again, the health-seeking processes were not streamlined, not straight, and frequently drawn out.

\subsection{Comments}

In 2012 and 2014, the general idea in Kanlagaun was that TB was well-known, common, and on the increase. The female manager of the main tea shop in the VDC centre proclaimed, "TB has become a normal disease. From child to old age, people know about the TB disease”. Even so, the mean delay in the 2012 and 2014 interview cohort was not shorter than that of the 2005 cohort!

In Kanlagaun in 2005, the link between infectious TB and other types of TB was not known. And, manifestations other than those of pulmonary TB seldom, if ever, referred to. Over time, public TB messages were extended to also include information on EP TB. To most Kanlagaun villagers this meant a likelihood of more TB cases being around than expected and thus an increased danger for transmissions. The latter because the fact of EP cases not being infectious had rarely been understood or taken to heart.

Yes, TB had become 'a normal disease', (mostly in the sense of being curable), at the same time, however, it was "a somewhat shameful disease" in the minds of people often connected with an unhealthy lifestyle, too much alcohol in particular. Additionally, in Kanlagaun, as in many parts of Nepal, there was and is a social disapproval of prolonged physical weakness. There are supernatural forces seeking inroads and serious ill-health is such an inroad. Moreover, for those labouring for others it was and is important to come across as strong and healthy. Thus, there were reasons to conceal and of late better means to do so than previously_a situation which further invited speculations as to the size of the problem.

A cultural unwillingness to openly share particulars of a serious sickness episode might well be the reason why TB patients set off on an arduous health-seeking route in spite of a next-door neighbour or even a relative having had similar signs and symptoms and ought to have been able to recommend a shorter route, that is, a direct one to the health establishment which had come up with his/her TB diagnosis. Another likely reason was the traditionally prescribed hesitation of 
getting oneself involved in other people's troubles.

What, then, about often long delays of those with other TB cases in the family/household? One obvious reason was and is that an infectious case does not necessarily give rise to the same type of TB in others, thus not a replica but variations in signs and symptoms. Moreover, in some families there was a considerable time span between cases and a carry-over was and is thought to manifest itself more or less immediately, like in the transfer of a cold. Perhaps equally important was and is the circumstance that in most cases the full representation of the disease, the commonly known cluster of TB signs, were not there in one go but developed over time and patients had reasons to believe that whatever was wrong was caused by having worked too hard, the weather being contrary to their constitution, and so on and so forth. Thus, most patients and household members testified to the suspicion of the condition possibly being TB presenting itself late, or not at all, and this even where there had been earlier TB cases in the family. And of course, neither the Kanlagaun villagers nor we are always rational in handling ill-health.

In the case of pulmonary TB, the persistent coughing was noticed but not necessarily perceived as a red flag as coughing is common in rural Nepal, partly because of smoke filled interiors but also widespread cigarette smoking. Fever at night and a loss of appetite were more worrisome but at least to start with quite easily explained by being anxious over this or that, too much alcohol, and so on.

A fundamental cause for delays was the need to work and not allowing oneself to be sick. When asked about the household's financial standing compared to other households in the village most respondents reported that it was lower than general, not an objective measurement but an indicator of them being aware that the household could ill afford a non-contributing member for a long period of time and particularly not when combined with help-seeking expenditures. Those with insufficient money had longer spells between the various health-seeking initiatives (outside the home) than those with money to spare. In the investigated cases, not much of the proudly declared mutual aid within the community in times of need was demonstrated. This was true not only in regard to the 2012 and 2014 cohort but also in regard to the previous one.

The patients of the 2012 and 2014 cohort like those of 2005 did not have long delays because of inactivity. The initial attempts, as among those of 2005, were various home-treatments, mostly herbal and dietary (Ayurvedic). In the earlier cohort the next step for at least half the patients were treatments within 'the folk sector' (traditional healers). Only after it proved itself insufficient was the search geared towards biomedical services. In the 2012 and 2014 cohort, the first choice outside the home was mostly within the biomedical sphere, 'the professional sector'. However, after initial failures within the same, several turned to 'the folk sector', i.e. as a second or a third choice. With subsequent failures there was a return to the biomedical sector. Thus, there was more of an oscillation between 'the folk' and 'the professional sector'.

A person on anti-TB medicines was not likely to have parallel consultations with a traditional healer but if there were additional health problems they did. Likewise, to have been cured from TB by chemotherapy was not a deterrent to consultations with a traditional healer for the next spell of ill-health.

In regard to the dhami/jhankri consulted in the health-seeking processes, we did not differentiate who had or had not participated in the three-day health training, basic TB information included, provided by the District Health Office. However, none of the patients interviewed reported that a traditional healer had suggested a medical check-up. Thus, health-seeking within the 'folk sector' again meant extended delays.

In spite of Biomedicine being a late-comer, the Kanlagaun villagers had a strong faith in its therapies (injections, antibiotics, and supplements in particular). 
However, the expectation was that the 'right medicine' would bring about an expedient recovery and when that did not happen the medicine was easily written off as the wrong one or as being out of date and the quest for the 'right medicine' and 'better medicines' was on.

Only one of the interviewed patients referred to a visit to the local pharmacy in the VDC headquarters. Yet, there might have been others as such visits were not a great undertaking and easily missed in recollections. Even so, the general idea obviously was that the best medical help was found in towns and cities.

Like in the previous cohort, most patients had visited not one but several private pharmacies. A few pharmacies had an arrangement with a medical officer and on and off there were examinations to be had. However, none of the patients interviewed in 2012 and 2014 reported any examinations except at nursing homes and in the hospitals. The necessity of precise information for right treatment when no physical examination is taking place had obviously not been understood nor taken to heart, neither among the health-seekers nor among many of those dispensing medicaments in private pharmacies. Thus, often little was said on either side of the counter and the chance of discerning what was wrong and its remedy was clearly limited. Even so, medicines were freely dispensed, not in regard to money but in regard to numbers (long lists of medicines and supplements). After all, private pharmacies are and were primarily money making businesses.

After the cessation of the INF 'TB hospital' the options within the district for a proper examination were nursing homes and the government Regional Hospital. Sometimes they did a good job, sometimes not. In the end, the majority of the TB diagnoses were made within the Regional Hospital, however, not necessarily in connection with the first consultation. Thus, like the patients of 2005, most patients in the 2012 and 2014 cohort reported not one but several faulty biomedical diagnoses. And, in the absence of the
'TB Hospital' the mean delay was actually somewhat longer than that of the 2005 cohort!

\section{Conclusions}

The ethnographic data highlight the difficulty for the patients, both rich and poor, men and women, young and old, to find their way to the tuberculosis diagnosis and that in spite of a widespread local knowledge of the most common signs and symptoms of TB and despite most of them being closely associated with persons presently or previously on anti-TB treatment.

In one sense each health-seeking route was unique, yet in another sense they were similar with health-seeking efforts within more than one of the main medical systems of Nepal: Ayurveda, Shamanism, and Biomedicine, each representing unique ideas of causation and treatment options. Cognitive dissonance between the sectors was clearly not a deterrent. A lack of informed choices, however, was and so was a lack of medical professionalism of most health institutions involved. Thus, health-seeking processes were commonly long, painful, and costly, and, of course dangerous: for the person affected by TB and, in the cases of infectious TB, for society.

Contrary to our expectations, circumstances had not improved over time. For a lasting success of the NTP anti-TB strategy, the prevalence and the mortality rates should steadily decrease. With long delays they will not. Interactions between health-seeking persons and health-service providers, private and public, must be better understood. And, reasons for the failure of recognized clinical services to diagnose symptomatic individuals need to be investigated and actions taken. Moreover, the documented clustering of patients is a call for improved communication between DOTS providers, the TB patients, and the community.

\section{References}

[1] Kleinman, A. 1986. Concepts and Models for the Comparison of Medical Systems as Cultural Systems. In Curer, C. et al. Concepts of Health, Illness and Disease, a Comparative Perspective. New York: Leamington 
Spa/Hamburg/.

[2] Basnet, R., et al. 2009. "Delay in Diagnosis of Tuberculosis in Nepal.” BMC Public Health 9: 236.

[3] Bhatt, C. P., et al. 2010. "Knowledge of Tuberculosis Treatment-a Survey among Tuberculosis Patients in (DOTS) Program in Nepal." SAARC Journal of Tuberculosis, Lung Diseases and HIV/AIDS 7 (2): 10-4.

[4] Choudhari, M., et al. 2012. "Factors Associated with Patient Delay in Diagnosis of Pulmonary Tuberculosis in a
District.” J. Nepal Health Res. Counc. 10 (22): 2034-8.

[5] Kumar, G. 2013. "Gender Based Barriers in Accessing Tuberculosis Treatment: a Qualitative Study from Eastern Nepal.” SAARC Journal of Tuberculosis, Lung Diseases \& HIV/AIDS X (2).

[6] Ten Asbroek, A. H. A., et al. 2008. "The Road to Tuberculosis Treatment in Rural Nepal: A Qualitative Assessment of 26 Journeys.” BMC Health Services Research 8: 7. 